\title{
DEFLUORIDATION USING EGG SHELLS AND RICE HUSK: KINETICS AND EQUILIBRIUM STUDIES
}

\author{
E Vasavi \\ Civil Engineering Department, Koneru Lakshmaiah Education Foundation University \\ (Deemed to be University), Guntur Andhra Pradesh, India \\ V Sree Lakshmi \\ Assistant Professor, Civil Engineering Department, Koneru Lakshmaiah Education \\ Foundation University (Deemed to be University), Guntur Andhra Pradesh, India
}

\begin{abstract}
Effects of fluoride in water is both beneficial and detrimental. So fluoride in higher levels must be removed. The present study works with the extraction of fluoride from aqueous solution using natural adsorbents prepared from rice husk and egg shells. Experiments were performed to demonstrate optimal conditions like $\mathrm{pH}$, adsorbent dose and contact period. Egg shells were found to be more effective than rice husk in terms of adsorbent dosage and contact period required. Data from the equilibrium studies was used to understand the order of kinetics and to predict the isotherms of the adsorption process.
\end{abstract}

Keywords: Fluoride, defluoridation, adsorption, biosrbents, egg shells, rice husk, adsorption isotherms

Cite this Article: E Vasavi and V Sree Lakshmi, Defluoridation Using Egg Shells and Rice Husk: Kinetics and Equilibrium Studies. International Journal of Advanced Research in Engineering and Technology, 10(5), 2019, pp. 65-72.

http://iaeme.com/Home/issue/IJARET?Volume $=10 \&$ Issue $=5$

\section{INTRODUCTION}

Fluorine is the $13^{\text {th }}$ most abundant element and is about $0.3 \mathrm{~g} / \mathrm{Kg}$ of earth's crust. It belongs to the halogen group with atomic number 9 and molecular weight 19. Fluoride having less radius /charge ratio is considered as the most electronegative element with low dissociation energy. This makes fluorine extremely reactive and has a strong affinity to combine in order to produce different compounds with other elements.

Fluorosis is distributed globally and endemic in 25 nations at least. High fluoride concentrations have been recorded in 230 districts in 20 Indian states (after Andhra Pradesh bifurcation in 2014).In India, fluorosis is primarily due to excess fluoride in water except in areas of Gujarat and Uttar Pradesh, where industrial fluorosis is also observed. 
In order to protect the generation yet to be born against fluorosis the only best solution would be to provide water with optimal fluoride content. This can be attained by the following methods defluoridation, location of alternative safe sources, supplying water from a distant safe source and minimize industrial fluoride pollution. Of these defluoridation technique is most commonly used. There are many methods of defluoridation like nalgonda technique, activated alumina adsorption, reverse osmosis etc. Each of these techniques have their own advantages and disadvantages. Research is going on to find the low cost and sustainable adsorbent materials.

In the present work natural adsorbents with locally available bio waste such as rice husk and egg shells was developed for fluoride extraction, which can be used as an alternative for various expensive defluoridation techniques. Present study aims at examining the fluoride removal efficiency and adsorption capacity of various natural materials from the water samples collected in the Nalgonda region of Telangana state.

Future Scope: From various studies it is found that the wastewater generated after defluoridation is not being disposed safely. So working on extraction of fluoride from defluoridated sludge will be the solution to this problem.

\section{METHODOLOGY}

\subsection{Equipment and Apparatus}

The DR 2700 Portable Spectrophotometer was used for fluoride ion measurement. SPADANS reagent was used in the process. The $\mathrm{pH}$ was evaluated using glass electrode with $\mathrm{pH} /$ ion meter. Every time measurements were produced, $\mathrm{pH}$ meter was gauged by $\mathrm{pH}$ calibration buffers.

\subsection{Reagents}

Reagents like $\mathrm{NaF}, \mathrm{NaOH}, \mathrm{HCl}, \mathrm{NaCl}, \mathrm{CH}_{3} \mathrm{COOH}$ (glacial), sodium citrate, EDTA, and concentrated $\mathrm{H}_{2} \mathrm{SO}_{4}$ of analytical grade were used in the entire experiment.

\subsection{Preparation of Materials}

\subsubsection{Rice husk}

Rice husk was collected from a local mill and the husk was sieved such that material passing through $300 \mu \mathrm{m}$ and retaining on $150 \mu \mathrm{m}$ was used for the study. Material so obtained after sieving was packed in a container with multiple pores on the surface is kept in muffle furnace at a temperature of $250^{\circ} \mathrm{C}$ for about 3 hours. The black husk now obtained was termed as RHAC (rice husk activated charcoal).

\subsubsection{Egg Shells}

From the local region, egg shells were collected and washed with distilled water and then dried. Then the dried shells were grounded and well sieved so that the fraction of material that passes through $300 \mu \mathrm{m}$ and retains at $150 \mu \mathrm{m}$ was used for the research.

\subsection{Equilibrium Studies}

Equilibrium adsorption studies were conducted with $250 \mathrm{ml}$ of sample water containing 12.5 $\mathrm{mg} / \mathrm{L}$ of fluoride concentration. Samples were transferred to a conical flask to which $10 \mathrm{~g}$ of each adsorbent was added. Samples were then shaken at $200 \mathrm{rpm}$ at room temperature for about 2 hours to reach the equilibrium state. After attaining equilibrium sample was filtered using whatman filter paper 1 and was then analyzed for fluoride ion concentration. Adsorption efficiency (\%) and equilibrium uptake capacity of each adsorbent was calculated using the following formulas. 
Defluoridation Using Egg Shells and Rice Husk: Kinetics and Equilibrium Studies

$$
\begin{gathered}
q e=\left(\frac{C o-C e}{m}\right) v \\
\text { removal efficiency } \%=\left(\frac{C o-C e}{C o}\right) 100
\end{gathered}
$$

Where $\mathrm{C}_{\mathrm{o}}, \mathrm{C}_{\mathrm{e}}$ are initial and equilibrium fluoride concentrations $(\mathrm{mg} / \mathrm{L})$ respectively, $\mathrm{m}$ is the mass of the adsorbents used in grams and $\mathrm{V}$ is the volume of the solution in litres.

\subsection{Preliminary Test}

Preliminary test was performed on adsorption efficiency of the adsorbents before undertaking the optimization experiment. For this $250 \mathrm{~mL}$ of sample with $12.5 \mathrm{mg} / \mathrm{L}$ of fluoride ion concentration was taken in the conical flask to which $10 \mathrm{~g}$ of each adsorbent was added. Samples were then shaken at a speed of $200 \mathrm{rpm}$. Then the samples were tested for fluoride concentration at different times $(0.5,1,1.5,2,2.5,3,4,5$, 6hours $)$.

\subsection{Optimization of Different Parameters}

Optimization was carried out to create those variable workbest by changing one variable while holding others as constants. Various parameters like adsorbent dose, contact time and $\mathrm{pH}$ were varied and were optimized.

\subsection{Effect of Adsorbent Dosage and Contact Time}

Experiments were carried with solutions of different adsorbent dosages varying from 3 to $18 \mathrm{~g} / 250 \mathrm{~mL}$ of rice husk and treated egg shell powder with initial fluoride concentration of 12.5 ppm at different contact periods ranging from 30 minutes to 6 hours. Adsorbent dosages were based on preliminary studies.

\subsection{Effect of pH}

The $\mathrm{pH}$ of the solution containing $12.5 \mathrm{ppm}$ of initial fluoride concentration was varied from 212 using $1 \mathrm{~N} \mathrm{HCL}$ and $1 \mathrm{~N} \mathrm{NaOH}$. To these solutions $12 \mathrm{~g}$ of egg shell powder was added and tested after 90 minutes. In case of adsorbent prepared from rice husk $15 \mathrm{~g}$ of it was added and tested after 2 hours. After each experiment residual fluoride was calculated.

\subsection{Adsorption Isotherms}

Langmuir and Freundlich isotherms were studied in the current discussion using modified adsorbents at room temperature. For plotting isotherms data was obtained from a solution containing initial fluoride concentration of $12.5 \mathrm{mg} / \mathrm{L}$ with a series of increasing adsorbent dosages of 3, 6, 9, 12, 15, 18g. Residual fluoride was calculated in each case after attaining equilibrium.

\subsubsection{Freundlich Isotherm}

Freundlich and Langmuir isotherms are helpful models for understanding adsorption process of various adsorbents. The Freundlich model relates to the adsorbent's surface heterogeneity, while the. Following equation represents the linear form of Freundlich isotherm

$$
\log q e=\log K f+\left(\frac{1}{n}\right) \log C e
$$

Where qe is the sum of fluoride ion adsorbed per unit adsorbent mass, mg / g; qe is the balance adsorbent concentration in solution, $\mathrm{mg} / \mathrm{L}$; $\mathrm{Kf}$ and $\mathrm{n}$ are Friendly constants indicating adsorption efficiency ( $\mathrm{mg} / \mathrm{g}$ ) and adsorption frequency, respectively. which were obtained by plotting a linear graph between $\operatorname{logqe}$ versus $\log C$ e. Values of $\mathrm{n}$ greater than 1 indicate favorable sorption. 


\subsubsection{Langmuir Isotherm}

Langmuir model assumes uniform adsorption energies on the surface and no adsorbent transmigration on the surface plane. Linear form of the Langmuir isotherm is given by the following equation

$$
\begin{aligned}
& \left(\frac{C e}{q e}\right)=\frac{1}{K l * q e}+\frac{C e}{q m} \\
& R l=\left(\frac{1}{1+K l * C o}\right)
\end{aligned}
$$

Where qe is the sum of fluoride ion adsorbed per unit adsorbent mass, mg / g; qm and K1 are constants of Langmuir representing the power of adsorption and binding strength, respectively. Langmuir constants are determined from the slope and intercept of linear plot of $\mathrm{Ce} / \mathrm{qe}$ versus $\mathrm{Ce}$. $\mathrm{Rl}$ is the separation factor whose values between 0 and 1 indicates favorable sorption, values greater than 1 indicates unfavorable sorption, value of 0 indicates irreversible sorption and value of 1 indicates linear sorption.

\subsection{Adsorption Kinetics}

Adsorption kinetics was studied using adsorbent dosage of 3, 6, 9, 12, 15 and $18 \mathrm{~g}$ corresponding to the initial fluoride concentration of $12.5 \mathrm{mg} / \mathrm{L}$. At different time intervals of $0.5,1,1.5,2,2.5,3,4,5$ and 6 hours residual fluoride concentrations are measured.

\subsubsection{Pseudo First Order Kinetics}

$$
\log (q t-q e)=\log q e-(k 1 / 2.303) t
$$

$\mathrm{q}_{\mathrm{e}}$ and $\mathrm{q}_{\mathrm{t}}$ are the quantity of fluoride ion adsorbed per unit mass of rice husk or egg shells $(\mathrm{mg} / \mathrm{g})$ at equilibrium and at any time respectively. When a straight line is plotted between $\mathrm{t}$ and $\log \left(\mathrm{q}_{\mathrm{e}}-\mathrm{q}_{\mathrm{t}}\right)$ slope and intercept of the equation gives $\log \left(\mathrm{q}_{\mathrm{e}}\right)$ and $\mathrm{k}_{1} / 2.303$ respectively where $\mathrm{k}_{1}$ is the rate constant of first order sorption $\left(\mathrm{min}^{-1}\right)$

\subsubsection{Pseudo Second Order Kinetics}

$$
t / q e=1 /(k 2 * q e 2)+t / q e
$$

$\mathrm{Q}_{\mathrm{e}}$ is the amount of fluoride ion adsorbed per unit mass of adsorbent $(\mathrm{mg} / \mathrm{g})$ at equilibrium. When a straight line is plotted between $t$ and $t / \mathrm{q}_{\mathrm{e}}$, slope and intercept of the equation gives $1 / \mathrm{q}_{\mathrm{e}}$ and $1 /\left(\mathrm{k}_{2} * \mathrm{q}_{\mathrm{e}}^{2}\right)$ respectively where $\mathrm{k}_{2}$ is the rate constant of second order sorption $\left(\mathrm{min}^{-1}\right)$

\section{RESULTS AND DISCUSSIONS}

\subsection{Preliminary Study}

Different adsorbents have varying adsorption efficiency under similar conditions for the same initial fluoride concentration. It was observed that with adsorbent prepared from egg shells efficiency was about $87 \%$ within 3 hours and similarly with adsorbent from rice husk efficiency was about $80 \%$ with same contact period. From the study it was clear that both the adsorbents have fluoride ion adsorption potential, but the contact time effects the percentage removal. 
Defluoridation Using Egg Shells and Rice Husk: Kinetics and Equilibrium Studies

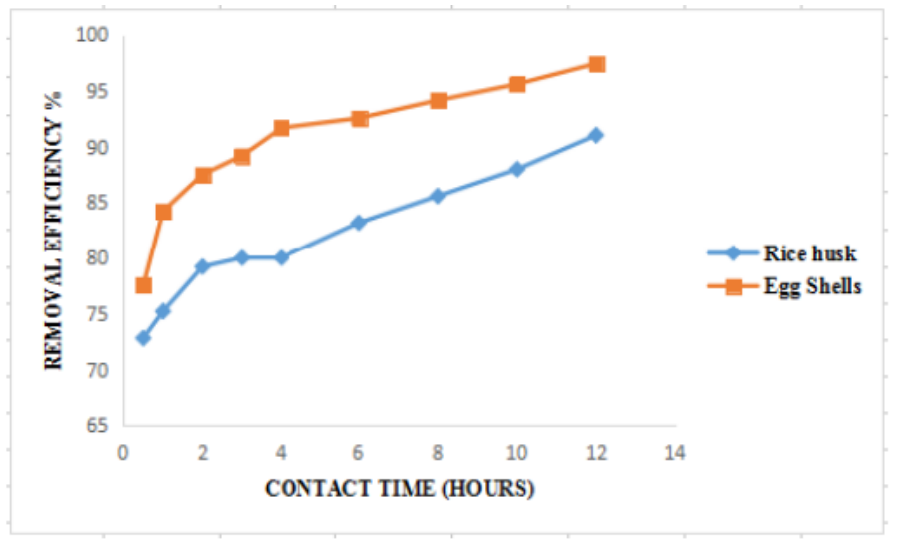

Figure 1 Effect of contact time on fluoride removal with initial fluoride concentration of $12.5 \mathrm{ppm}$ and adsorbent dose of 10 grams.

\subsection{Adsorbent Dose and Contact Time}

From the fig 2 we can say that for both the adsorbents concentration of residual fluoride decreases with the contact time. Over $50 \%$ of the initial concentration of fluoride was reduced for all doses of treated rice husk and egg shell powder in the first half an hour. The fluoride removal rate became slow after 30 minutes. This was because at the beginning adsorbent has active sites that are free which resulted in high removal efficiency and later on because of congestion of the active sites, this decreases with increasing contact time. Increase in removal rate of fluoride with increase in adsorbent dose was also observed due to availability of more active sites.

Using treated rice husk about $80 \%$ removal efficiency was attained within half an hour with $15 \mathrm{~g}$ of adsorbent dosage and with contact time greater than 3 hours fluoride concentration became lower than the limits. Therefore the optimum conditions were considered as contact time of 2 hours and dosage of $15 \mathrm{~g}$. In case of egg shell powder $80 \%$ efficiency was attained within half an hour using $12 \mathrm{~g}$ of dosage and with increase in contact period above 4 hours fluoride concentration has fallen below the prescribed limits. Therefore optimum conditions for egg shell powder were considered as 1.5 hours contact time and $12 \mathrm{~g}$ dosage.

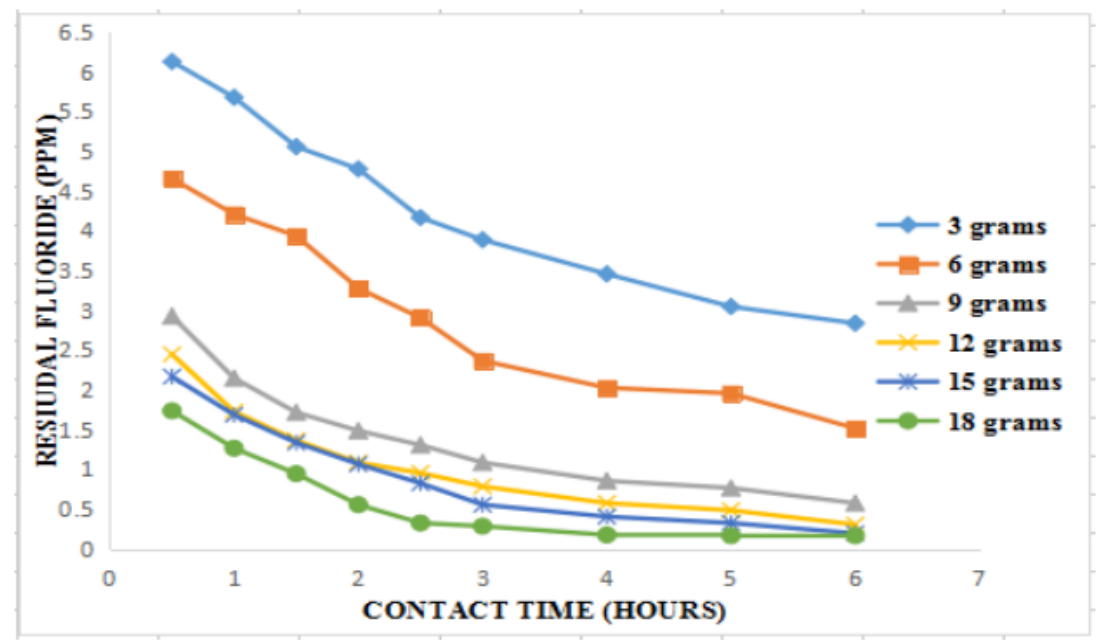

Figure 2 Effect of contact time and adsorbent dosage (egg shells) on fluoride removal; initial fluoride concentration of $12.5 \mathrm{ppm}$. 


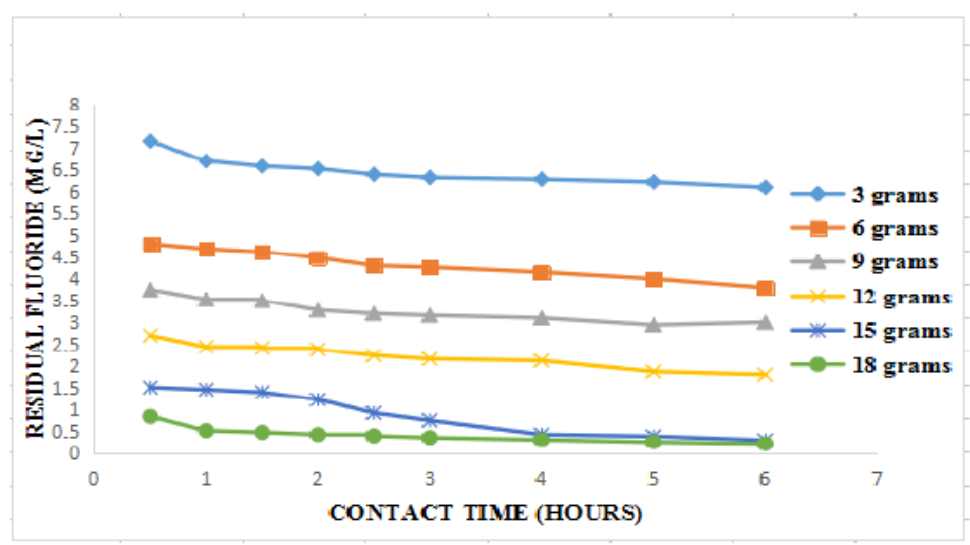

Figure 3 Effect of contact time and adsorbent dosage (rice husk) on fluoride removal; initial fluoride concentration of $12.5 \mathrm{ppm}$.

\subsection{Effect of pH}

From the fig 4 it can be seen that with increase in $\mathrm{pH}$ there was a decrease in fluoride removal efficiency. At optimum conditions of dosage and contact time same pattern was observed for both the adsorbents.

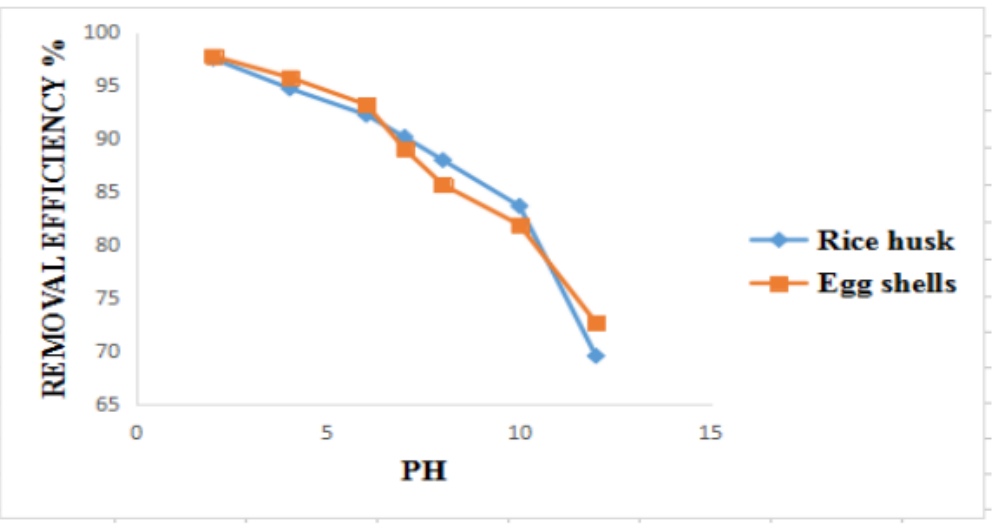

Figure 4 Effect of $\mathrm{pH}$ on fluoride removal with initial fluoride concentration of $12.5 \mathrm{ppm}$

\subsection{Adsorption Isotherms}

The linear form of the Freundlich equilibrium isotherm mode represented the adsorption process well for both the adsorbents with $\mathrm{R}^{2}$ values of 0.9582 and 0.9814 for egg shells and rice husk respectively; table 1 , and the values of $n$ for both the adsorbents was greater than 1 indicating favorable sorption.

Table 1: Freundlich isotherm parameters and correlation coefficients

\begin{tabular}{|l|c|c|c|}
\hline Adsorbents & $\mathbf{n}$ & $\mathbf{K}_{\mathbf{f}}$ & $\mathbf{R}^{\mathbf{2}}$ \\
\hline Egg shells & 2.15 & 0.4647 & 0.9582 \\
\hline Rice husk & 1.602 & 0.1723 & 0.9814 \\
\hline
\end{tabular}

Table 2 Langmuir isotherm parameters and correlation coefficients

\begin{tabular}{|c|c|c|c|}
\hline Adsorbents & $\mathbf{K}_{\mathbf{a}}$ & $\mathbf{q m}_{\mathbf{m}}$ & $\mathbf{R}^{\mathbf{2}}$ \\
\hline Egg shells & 3.375 & 0.928 & 0.8804 \\
\hline Rice husk & 0.6395 & 0.981 & 0.841 \\
\hline
\end{tabular}


$\mathrm{R}^{2}$ values of Langmuir isotherm were 0.8804 and 0.841 for egg shells and rice husk respectively and the separation factor $\mathrm{Rl}$ was found to be between 0 and 1 ; table 2 indicating favorable sorption.

\subsection{Adsorption Kinetics}

Compared to the first-order reaction, the pseudo-second order equation fitted experimental data well with and $\mathrm{R}^{2}$ value approaching to unity; table 4 .Based on the correlation coefficients, a second-order reaction pathway is followed by biosorption of fluoride ions by both egg shells and rice husk.

Table 3 Coefficients of pseudo first order reaction and correlation coefficients

\begin{tabular}{|l|c|c|}
\hline \multicolumn{1}{|c|}{ Adsorbents } & $\mathbf{K}_{\mathbf{2}}$ & $\mathbf{R}^{\mathbf{2}}$ \\
\hline Egg shells & 2.2189 & 0.9996 \\
\hline Rice husk & 2.2836 & 0.99994 \\
\hline
\end{tabular}

Table 4 Coefficients of pseudo second order reaction and correlation coefficients

\begin{tabular}{|l|c|c|c|}
\hline Adsorbents & $\mathbf{q}_{\mathbf{e}}$ & $\mathbf{K}_{\mathbf{1}}$ & $\mathbf{R}^{\mathbf{2}}$ \\
\hline Egg shells & 0.256 & 0.5071 & 0.9774 \\
\hline Rice husk & 0.205 & 0.5062 & 0.9642 \\
\hline
\end{tabular}

\section{CONCLUSIONS}

This study showed that thermally treated adsorbents made from rice husk and egg shells were ideal for fluoride ion extraction. The operational parameters such as adsorbent dose, contact time and $\mathrm{pH}$ were found to have an effect on the adsorption efficiency. All other parameters were found to be same even after defluoridation. Optimum conditions were found to be $12 \mathrm{~g}$ of egg shells with contact period of 90 minutes and $15 \mathrm{~g}$ of rice husk with contact period of 3 hours. Under optimum conditions adsorbents prepared from rice husk and egg shells displayed the highest efficiency of 90 and 89 percent fluoride extraction, respectively, for an initial concentration of $12.5 \mathrm{mg} / \mathrm{L}$. For both the adsorbents optimum $\mathrm{pH}$ was found to be 6 .Egg shell was observed to be much more effective than rice husk in terms of time and adsorbent dose required. The adsorption mechanism approaches Freundlich adsorption isotherm in both cases. Adsorption of fluoride by both the adsorbents was best followed by pseudo second order reaction.

\section{REFERENCES}

[1] Abdisa Gebisa Jebessa. "Preparation and Evaluation of Adsorption Effectiveness of Peanut Husk for the Removal of Fluoride Ion from Aqueous Solution" Volume 6, Issue 3, 2018, pp. $2-5$

[2] Dr. Ch. Kannam Naidu, Dr. Ch. Vasudeva Rao, Dr. G. Venkata Rao and A.Y.D.T. Akhilesh, Experimental Study on M30 Grade Concrete with Partial Replacement of Cement with Egg Shell Powder, International Journal of Civil Engineering and Technology, 9(5), 2018, pp. $575-583$.

[3] Achla Rani, Dr. Rajeev Sharma and Dr. Archana Tomar. "Defluoridation of Water using Mosambi Peel Powder as Adsorbent: Kinetics and Equilibrium Studies", Vol. 8, Issue 4, 2018, pp. $17284-17288$.

[4] V.Sakthi Murugan, Rathan Kumar, Y.Suresh, M.Kumaragnanamithra, Raveen rohith and M.Viswanathan, Kaleem Sherif, A numerical approach to Suspension Kinetics Analysis of FSAE Car, International Journal of Mechanical Engineering and Technology, 8(10), 2017, pp. $910-917$. 
[5] Anil k. Shrivastava and manoj k. Sharma. "An innovative technique for removal of fluoride from drinking water" vol. 2, issue 2, 2012, pp. 133-134.

[6] Abraham Kanmognea, Oumarou Hamandjodaa, Jean Nganhoua and Bienvenu Kenmeugne, Experimental Study of Cocoa Drying Kinetics with a View to Modelling a Dryer, International Journal of Advanced Research in Engineering and Technology (IJARET), Volume 5, Issue 1, January (2014), pp. 154-163.

[7] A.S. Parlikar and S.S. Mokashi. "Defluoridation Of Water by Moringa Oleifera a Natural Adsorbent" Vol. 2, Issue 5, 2013, pp. 245-252.

[8] Kishore Bingi and Susy Thomas, A New Chaotic Attractor Generated from a 3-D Autonomous System with one Equilibrium and its Fractional Order Form, International Journal of Electrical Engineering and Technology (IJEET), Volume 5, Issue 2, February (2014), pp. 51-59.

[9] Kavita Panchore, Dr. Sarita Sharma, Dr. Ashok Sharma and Dr. Sanjay Verma. "Studies on removal of fluoride from drinking water by using brick powder adsorbent," Vol. 2, Issue 6, 2016, pp. 153-156.

[10] Nedunuri Phani Kumar, Nadavala Siva Kumar and Abburi Krishnaiah. "defluoridation of water using tamarind (tamarindus indica) fruit cover: kinetics and equilibrium studies" Vol. 57, Issue 3, 2012, pp. 1224-1231.

[11] Sanghratna S. Waghmare and Tanvir Arfin. "Fluoride Removal from Water by various techniques: Review" Vol. 2, Issue 9, 2015, pp. 562-571.

\section{ABOUT AUTHORS}

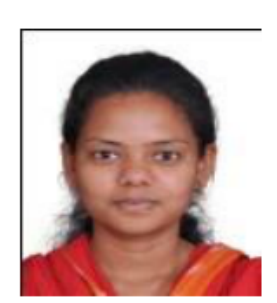

E VASAVI received B. Tech Degree in Civil Engineering from Koneru Lakshmaiah Education Foundation University (Deemed to be University), Guntur Andhra Pradesh, India in 2017. She is Pursuing M. Tech degree in Environmental Engineering form KLEF Deemed to be University, Guntur, Andhra Pradesh, India. She actively participated in workshops and seminars in and around the University.

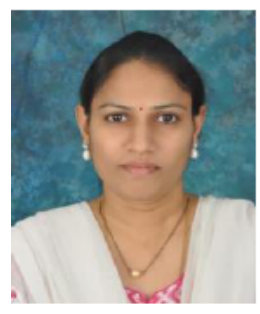

SREE LAKSHMI V working as an Assistant Professor in Civil Engineering Department, Koneru Lakshmaiah Education Foundation (Deemed to be University), Vaddeswaram has completed her Bachelor of Technology from Civil Engineering in DMSSVH college of Engineering, Machilipatnam and later finished her masters from Andhra University college of Engineering, Visakhapatnam. She have published various papers and guided many students for their projects. 